\title{
Effect of self-care counselling on depression and anxiety in women with endometriosis: a randomized controlled trial
}

Nooshin Farshi', Shirin Hasanpour ${ }^{2 *}$, Mojgan Mirghafourvand ${ }^{3}$ and Khali Esmaeilpour ${ }^{4}$

\begin{abstract}
Background: Considering the prevalence of endometriosis and consequent depression and anxiety as well as the resultant effects on the body, mind, and quality of life of patients, this study aimed to determine the effects of selfcare counselling on depression and anxiety (primary outcome) and on quality of life (secondary outcome) among women with endometriosis.
\end{abstract}

Method: This randomized controlled clinical trial was conducted on 76 women with endometriosis who were treated at Al-Zahra Teaching and Treatment Center of Tabriz within the 2015-2019 period. The random blocking method was employed to divide the patients into intervention (counselling) and control groups. In the intervention group, seven self-care group counselling sessions were held on a weekly basis. The control group received routine care. A sociodemographic questionnaire, Beck Depression Inventory, Spielberger State-Trait Anxiety Inventory (STAI) and the SF-36 Quality of Life Questionnaire were completed by the researcher through an interview before and 4 weeks after the intervention.

Results: There was no significant difference between the intervention and control groups in terms of sociodemographic characteristics $(p>0.05)$. After the intervention, the mean scores of state anxiety (mean difference: $-0.12,95 \%$ confidence interval: -9.6 to $-14.4, p<0.001$ ) and trait anxiety (mean difference: -10.9 : $95 \%$ confidence interval: -9.1 to $-12.7, p=0.001$ ) were significantly lower in the counselling group than those of the control group. The mean score of depression was lower in the counselling group than in the control group; however, it was not significant $(p=0 / 565)$. The mean score of quality of life for physical health (mean difference $=$ 17.2, 95\% confidence interval: 13.8 to 20.5, $p<0.001$ ) and for mental health (mean difference $=12.0,95 \%$ confidence interval: 9.0 to $14.9, p<0.001$ ) were significantly higher in the counselling group than in the control group.

Conclusion: Self-care counselling affects the anxiety and quality of life of women with endometriosis. Therefore, in addition to other therapies, this method is proposed to improve quality of life and mental health of patients with endometriosis.

\footnotetext{
* Correspondence: shirinhasanpoor@yahoo.com

Women's Reproductive Health Research Center, Tabriz University of Medical Sciences, Tabriz, Iran

Full list of author information is available at the end of the article
}

(c) The Author(s). 2020 Open Access This article is licensed under a Creative Commons Attribution 4.0 International License, which permits use, sharing, adaptation, distribution and reproduction in any medium or format, as long as you give appropriate credit to the original author(s) and the source, provide a link to the Creative Commons licence, and indicate if changes were made. The images or other third party material in this article are included in the article's Creative Commons licence, unless indicated otherwise in a credit line to the material. If material is not included in the article's Creative Commons licence and your intended use is not permitted by statutory regulation or exceeds the permitted use, you will need to obtain permission directly from the copyright holder. To view a copy of this licence, visit http://creativecommons.org/licenses/by/4.0/ The Creative Commons Public Domain Dedication waiver (http://creativecommons.org/publicdomain/zero/1.0/) applies to the data made available in this article, unless otherwise stated in a credit line to the data. 
(Continued from previous page)

Trial registration: IRCT Registration Number: IRCT 20111219008459 N13, registered on February 10, 2019 (https:// irct.ir/user/trial/35915).

Keywords: Self-care counselling, Anxiety, Depression, Quality of life, Endometriosis

\section{Background}

Endometriosis is the second most common gynecological disease, defined as a benign, estrogen-dependent inflammatory disease characterized by the presence and growth of endometrial-like glands and stroma outside the uterine cavity $[1,2]$. The etiology of this disease is still unknown. However, some theories have been proposed to explain endometriosis pathogenesis including changes in the immune system, celomic metaplasia (transformation of the germinal epithelium into ovarian endometriosis), benign metastasis (spread of endometriosis), and retrograde menstruation [3]. Accumulating evidence indicates that immune cells, adhesion molecules, extracellular matrix metalloproteinase, and pro-inflammatory cytokines activate or alter peritoneal microenvironment and provide the conditions for differentiation, adhesion, proliferation, and survival of ectopic endometrial cells [4-7]. Although the exact incidence of endometriosis is still unknown, approximately $2-10 \%$ of women of reproductive age and nearly $50 \%$ of women with pelvic pain are linked to endometriosis $[8,9]$. Based on the available knowledge, $47 \%$ of women referred for infertility problems have endometriosis [10]. Endometriosis was reported in premenarcheal girls [11] and also in 2$5 \%$ of postmenopausal women [12].

Symptoms and severity of endometriosis vary in location, spread, and depth of lesions $[8,13]$. The most common symptoms are pain, reduced fertility, gastrointestinal and bladder complications, and heavy and prolonged menstrual bleeding [14]. There is currently no satisfactory therapy for endometriosis. The symptoms (e.g. pain) are relieved with either medication or surgery [15]. The endometriosis treatment aims mainly to relieve pain, improve quality of life, prevent recurrent endometriosis, preserve fertility, and reduce anatomical impact $[16,17]$.

The chronic nature of endometriosis and potential impacts of its symptoms expose patients to the risk of developing mental disorders. Endometriosis-associated infertility has negative impacts on both marital relationships and social activities [18]. Painful sex and sexual dysfunction (consequences of endometriosis) also have adverse effects on the quality of life, marital relationships and self-confidence and can cause mental disorders [19, 20]. Other endometriosis-associated symptoms including dysuria, dysmenorrhea, dyspareunia, and pelvic pain alleviate the mental health of patients [21, 22]. Overlapping impacts of endometriosis on different aspects of life (physical, psychological, reproductive, communicational, and quality of life) of women allow no separate analysis of these impacts [23]. Endometriosis also has negative impacts on job and education [24, 25].

The relationship between endometriosis, depression and anxiety has been shown in different studies, which indicates the importance of pain perception in developing mood disorders in these women [26, 27]. Laganà et al. indicated high levels of psychiatric disorders (especially somatization, depression, and anxiety) in women suffering from endometriosis [28]. The quality of life of many patients with endometriosis is affected by pain, feelings of fertility loss, anger at disease recurrence, and uncertainty about the future due to the need for reoperation or long-term therapies [29]. Pope et al. stated that endometriosis was accompanied with a wide range of mental disorders, especially depression, anxiety, stress, and low quality of life [21]. Depression, anxiety, and quality of life of patients with endometriosis were assessed in a prospective study. The results showed that $86.5 \%$ of the patients developed symptoms of depression. They also found a positive relationship between severity of pain and anxiety [30].

Counselling with self-care focus contributes greatly to the treatment of chronic diseases. Recent studies have shown that patient-oriented counselling encourages patients to actively participate in treatment programs and promotes their positive outcomes [31, 32]. Self-carebased counselling helps the patients to control emotions, adhere to the therapy, understand the treatment rationale, improve quality of life, decrease stress, reduce anxiety, feel more secured, and increase life satisfaction [33]. Adequate knowledge of the chronic disease helps patients combat the disease. Therefore, the type and style of counselling for chronic diseases contribute significantly to the treatment of patients [34, 35].

According to the American Society for Reproductive Medicine, endometriosis should be viewed as a chronic disease requiring a life-long personalized management plan [36]. Patients with chronic illnesses are inevitably in charge of their own daily care. Therefore, they can determine the severity of their symptoms and effects of each type of treatment [36, 37]. According to the World Health Organization, self-care is defined as "the ability of individuals, families, and communities to improve health, prevent disease, maintain health, and cope with illness and disability either with or without the support of caretakers". Self-care is a self-guided active practice 
required to prevent short-term and long-term complications [38]. It shows that the person is responsible for health-related behavior and activities needed to control and assess individual health [39]. Self-care for chronic diseases helps maintain physical and mental health, reduce mortality rates, decrease healthcare costs, increase patient satisfaction, and improve quality of life [37, 40].

Current non-surgical treatments for endometriosis (e.g. non-steroidal anti-inflammatory drugs, oral contraceptive pills, and hormonal therapies) limit efficacy [41], and approximately $25-50 \%$ of patients discontinue treatment due to adverse effects of medication [42]. Therefore, women with endometriosis tend to practice selfcare and lifestyle interventions to relieve some of the symptoms or avoid side effects of the medications [43]. Self-care is a conscious self-regulatory learning practice needed to supply and maintain necessary resources in order to preserve physical, mental, social, spiritual function and growth for survival. It is a life-long practice at in all aspects [44].

Given the importance of psychological outcomes of endometriosis and insufficient assessment of impacts of self-care counselling on depression and anxiety in women with endometriosis, the authors decided to conduct a study to determine the impacts of self-care counselling, based on Orem's model, on depression, anxiety (primary outcome), and quality of life (secondary outcome) in women with endometriosis.

\section{Method}

\section{Research design and participants}

This study is a randomized-controlled trial, based on the CONSORT guideline with single-blinding (the analyzer of outcomes was blinded to the study groups) and two parallel arms with 1:1 allocation ratio. It was conducted on 76 women with endometriosis aged between 15 and 45 years and hospitalized at Al-Zahra Teaching and Treatment Center of Tabriz within the 2015-2019 period. The inclusion criteria were residing in Tabriz, having at least secondary school education degrees, being diagnosed with endometriosis via laparoscopy during the past 5 years, being in the range of $15-45$ years age, and being accessible vie fixed phone or cellphone numbers. The exclusion criteria were any condition that increased the risk of anxiety and depression (e.g. irritable bowel syndrome, migraine, and autoimmune disease ...), intake of antidepressants in the past 3 months, malignancies according to the patient, severe depression $(29<$ depression scores $<63$ ) and very severe anxiety (state anxiety scores $>75$ and trait anxiety scores $>72$ ), a recent trauma (e.g. death of relatives or divorce) increasing the risk of developing mental disorders, speech or hearing disorders complicating communication with the researcher, being pregnant after being diagnosed with endometriosis, and a history of past mental illness or a history of hospitalization for the same reason.

G-Power was employed to selected 35 participants as the research sample, based on the study by Waller et al. [45], by taking into account the depression variable and the largest standard deviation of depression subscales $(\mathrm{m} 1=11.8, \mathrm{~m} 2=7.2$ with the assumption of $35 \%$ reduction in the depression score due to intervention, $\mathrm{sd} 1=$ $\mathrm{sd} 2=6.6, \alpha=0.05$ and power $=80 \%$ ). The sample size was determined 38 by taking into account $10 \%$ sample loss.

\section{Sampling and randomization}

The participants were selected after the license from the ethics committee of Tabriz University of Medical Sciences was obtained (ethical code: REC.1397, 625 TBZMED.IR) when the study was registered on the Iranian Registry of Clinical Trials (IRCT 20111219008459 N13). The researcher visited Al-Zahra Teaching and Treatment Center of Tabriz, prepared a list of women with endometriosis hospitalized in the center during the past 5 years based on medical records, and contacted the patients via phone calls to explain the research objectives and design. In a face-to-face meeting with eligible patients, the research objectives and design were then thoroughly explained, and informed written consent forms were obtained. The sociodemographic questionnaire, Beck Depression Inventory (BDI-II), Spielberger State-Trait Anxiety Inventory (STAI), and the Quality of Life Questionnaire (SF-36) were completed in the interviews. The patients with mild to severe anxiety (32-75 state anxiety scores and 32-72 trait anxiety scores) and mild to moderate depression (14-28 depression scores) were enrolled in the study.

The patients were divided into intervention (counselling) and control groups by using stratified block randomization (with blocks of 4 and 6) based on infertility history via the www.random.org website. The intervention was written down on a paper and placed in sequentially numbered opaque sealed envelopes by a person who was not involved in sampling and data analysis in order to conceal the allocation sequence. The envelopes were given to the participants in order of arrival. For stratification based on infertility history, half of the envelopes were allocated to people with a history of infertility, whereas the other half were allocated to people without a history of infertility; therefore, the group type was determined.

\section{Intervention}

For the intervention group, self-care group counselling was conducted based on Orem's self-care model in seven 60-90-min sessions in the native language on a weekly basis at Al-Zahra Training and Treatment Center in a 
relaxing and friendly environment. There were 7-8 participants in each session.

Orem's Self-Care Theory, known as a grand theory, has effectively been used on some of chronic diseases such as diabetes, coronary artery disease, and cancer. Orem's theory focuses on each individual's ability to perform self-care, identifying patients' needs and the role of groups' structured relationships as well as defined tasks and allocated responsibilities for providing group members with healthcare [46]. Therefore, in this study group, counseling self-care protocol was designed based on general care needs of women with endometriosis and Orem's self-care model.

\section{Contents of the sessions are as follows First session}

The number and duration of each session, the interval between sessions, the rules governing the sessions, definition and concept of endometriosis, etiology, diagnostic methods, current treatment methods, and complications were explained to the patients in this introduction session. An educational booklet was also distributed among the patients.

\section{Second session}

The concept and importance of self-care were explained to the patients in a simple tone. Self-care skills and aspects (e.g. physical, psychological, social, and spiritual aspects of self-care) were also paraphrased.

\section{Third session}

Necessary training was given in proper and healthy diet. It was recommended to eat fresh and organic (natural) food, and their diet should be rich in antioxidants (vitamins A, C, E, etc.), high in fruits and vegetables, low in saturated fats, and rich in anti-inflammatory substances (e.g. broccoli, avocados, flaxseed, and flaxseed oil).

\section{Fourth session}

The importance of physical exercise in healthy lifestyle and relief of endometriosis symptoms (especially pain) were explained in a simple tone to cover the role of exercise in improving blood flow, releasing endorphin (a hormone that makes the body feel good), lowering estrogen levels, improving sleep, and reducing stress, anxiety and depression.

The proper medication regimen (e.g. timing and amount of medication) was also discussed, and it was recommended that medications should be taken regularly under the supervision of a doctor and that they should never arbitrarily increase, decrease, or stop the use of medications. The key points were repeated at the end of each session.

\section{Fifth session}

Non-pharmacological pain management therapies (e.g. yoga and massage) were explained, and the factors worsening the endometriosis symptoms and harmful practices were also explained and was recommended to be avoided (e.g. alcohol, caffeine, red meat, fast foods, and processed foods).

\section{Sixth session}

The self-care aspects and their impacts on physical and mental health were explained to the participants:

Physical self-care includes exercise, healthy diet, adequate sleep, and avoidance of high-risk behavior.

Psychological self-care includes the desire to live, consideration of leisure time, enjoyment of life.

Social self-care includes having social activities, maintaining friendships, and participating in fun activities with family and friends.

Spiritual self-care involves a close relationship with God.

\section{Seventh session}

In this session, participants' questions on all areas of selfcare were answered, and the ambiguities were removed.

The group facilitator was a member of the research team who was totally aware of the educational content of meetings, was acquainted with counselling rules, and had the necessary skills to involve everyone in the meeting and provide an environment of empathy, intimacy, and respect.

The control group received routine care. The Beck Depression Inventory, the Spielberger Anxiety Inventory, and SF-36 Quality of Life Questionnaire were completed by the researcher through an interview via phone calls 4 weeks after the intervention ( 12 weeks after the initial assessment).

\section{Data collection tools}

The abovementioned tools were employed to collect data.

The sociodemographic questionnaire was utilized to collect data on age, marital status, duration of marriage, number of children, history of infertility, history of treatments for infertility, women's desire to be pregnant again, ethnicity, education, occupation, spouse's education, spouse's occupation, adequacy of income to cover life expenses, place of residence, life satisfaction, duration of endometriosis, time of diagnosis, treatment methods, and post-treatment status. This was a researcher-made questionnaire, the content validity of which was confirmed by 10 faculty members of Tabriz University of Medical Sciences.

Beck depression inventory The Beck Depression Inventory was developed by Beck et al. in 1996. It contains 21 
items that assesses all domains of depression based on the cognitive theory of depression. Each item has four options. The individuals reveal their feelings and behavioral characteristics by answering each question. Each option is scored from 0 to 3 depending on the severity of symptoms. The scores range from 0 to 63 . The inventory can be applied to the members of populations aged above 13 because it assesses both incidence and severity of depression. This scale reflects feelings during the past 2 weeks. Scores ranging between 0 and 13 represent minimal depression, whereas $14<$ scores $<19$ represent mild depression, and $20<$ scores $<28$ represent moderate depression. Moreover, $29<$ scores $<63$ represent severe depression [47]. Rajabi et al. assessed reliability of the Beck Depression Inventory-Second Edition by calculating Cronbach's alpha coefficient. Alphas for the whole questionnaire, the first factors (cognitive-affective), and the second factors (negative attitudes-somatic symptoms) were reported as $0.86,0.84$, and 0.87 , respectively. These coefficients were acceptable and showed homogeneity of the subscales. The correlation coefficients of the whole scale with the first and second factors were 0.90 and 0.95 , respectively. The correlation between the first and second factors was reported as 0.75 ; these coefficients were significant at $p<0.001$ [48].

State-trait anxiety inventory (STAI) This is a standard questionnaire, the reliability of which was confirmed in previous studies. The scale used in this study contained 40 self-report items ( 20 for the state anxiety and 20 for trait anxiety). The state anxiety is scored on a four-point Likert scale (1) very low, (2) low, (3) high, and (4) very high). The trait anxiety is also scored on a four-point Likert scale ((1) almost never, (2) sometimes, (3) often, and (4) almost always). The minimum and maximum scores were 20 and 80 , respectively. Items $1,2,5,8,10$, $11,15,16,19,20,21,23,26,26,27,30,33,34,36,36,39$ were scored inversely [49]. In state anxiety, $20<$ scores $<$ 31 represent mild anxiety, whereas $32<$ scores $<53$ represent moderate anxiety. Moreover, $54<$ scores $<64$ represents relatively severe anxiety, whereas $65<$ scores $<75$ represent severe anxiety, and scores $>75$ represent very severe anxiety. In trait anxiety, $20<$ scores $<31$ represent mild anxiety, whereas $32<$ scores $<52$ represent moderate anxiety. Furthermore, $53<$ scores $<62$ represent relatively severe anxiety, whereas $63<$ scores $<72$ represent severe anxiety, and scores $>72$ represent very severe anxiety. Mahram et al. standardized the scale for Iranian population and reported Cranach's alpha as 0.91 [50].

The short form health survey questionnaire (SF-36) The SF-36 Quality of Life Questionnaire is the most popular instrument for measuring the quality of life. It was developed in the United States and translated into different languages. It measures 8 health-related concepts, namely physical functioning (10 items), role limitation due to physical reasons (4 items), physical pain (2 items), public health (5 items), vitality (4 items), social functioning ( 2 items), role limitations due to emotional reasons (3 items), and mental health (5 items). An item indicating change in public health per year was added to this questionnaire. The score of each dimension was determined by the score of items included in the same dimension. Reliability and validity of the questionnaire was checked by Montazeri et al. in Iran in 2005. They introduced it as a reliable and valid instrument for measuring public health-related quality of life [51].

The reliability of each questionnaire was determined by using test-retest on a sample of 20 women meeting the research eligibility criteria within a two-week interval by calculating Cronbach's alpha and the intra-class correlation coefficient in the present study. The intra-class correlation coefficients of Beck Depression Inventory, State Anxiety Inventory, Trait Anxiety Inventory, and SF-36 Quality of Life Questionnaire were reported as 0.91, 0.88, 0.83, and 0.93, respectively. The Cronbach's alphas were also reported as $0.87,0.78,0.72$, and 0.91 , respectively.

\section{Statistical analysis}

Data analysis was performed in SPSS 21, and quantitative data normality was determined through the Kolmogorov-Smirnov. All of the variables were normal except the depression. Chi-square, Trend chi-square, Fisher's exact tests and the independent $t$-test were conducted to assess homogeneity of the groups in terms of personal and social characteristics. The independent $t$ test was conducted to compare the mean scores of anxiety, depression and quality of life between the two groups before the intervention. ANCOVA was employed to compare the scores between the two groups within a four-week interval by controlling the baseline values. The Mann-Whitney $U$ test was employed to assess the variables with abnormal distribution. All analyses were based on the intention-to-treat method, in which $P<$ 0.05 was considered significance level.

\section{Result}

There were 332 female participants with endometriosis aged between 15 and 45 years and hospitalized at $\mathrm{Al}$ Zahra Teaching and Treatment Center of Tabriz within the 2015-2019 period. Among them, 256 people failed to meet the inclusion criteria, whereas $76 \%$ of them were randomly assigned to the counselling [38] and control [38] groups. Three patients of the control groups left the study ( 1 person was not available at follow-up time, and 2 people refused to fill out the questionnaires). Therefore, 38 participants in the counselling group and 35 
participants in the control group were assessed in follow-up step (Fig. 1).

There was no significant difference between the intervention and control groups in terms of personal social characteristics (Table 1).

The median (first and third quartiles) score of depression was $18.0(14.7-30.0)$ in the counselling group, whereas it was $17.0(14.7-25.2)$ in the control group before the intervention. There was no significant difference between the two groups in terms of depression according to the Mann-Whitney $U$ test $(P=0.645)$. The median (first and third quartiles) score of depression was $12.0(7.7-23.0) 4$ weeks after the intervention in the counselling group, whereas it was 11.0 (7.0-19.0) in the control group. The MannWhitney $U$ test results showed no significant difference between the groups in terms of depression by controlling baseline values $(P=0.565)$ (Table 2).

There was no significant difference between the groups in terms of state anxiety before the intervention according to the independent t-test $(p=0.507)$. The mean (standard deviation) of state anxiety score was 44.8 (10.4) before the intervention, whereas it was 35/ $1(8 / 0) 4$ weeks after the intervention in the counselling group. The mean (standard deviation) of state anxiety score was 43.2 (10.6) before the intervention, whereas it was 47.1 (10.2) 4 weeks after the intervention in the control group. The ANCOVA test results showed significant differences between the two groups in terms of state anxiety score by controlling baseline values (mean difference: -0.12 , $95 \%$ confidence interval: -9.6 to $-14.4, p<$ 0.001 ). There was no significant difference between the two groups in terms of trait anxiety before the intervention $(P=0.136)$. The mean (standard deviation) score of trait anxiety was 44.9 (9.9) before the intervention, whereas it was $37.0(8 / 2) 4$ weeks after the intervention in the counselling group. The mean (standard deviation) score of trait anxiety was 41.7 (8.8) before the intervention, whereas it was and 45.6 (9.1) 4 weeks after the intervention in the control group. ANCOVA test results showed significant difference between the two groups in terms of trait anxiety score by controlling baseline values (mean difference: - 10.9: 95\% confidence interval: -9.1 to $-12.7, p<0.001$ ) (Table 3 ).

Table 4 represents the qualitative comparison of depression and anxiety levels before and 4 weeks after intervention between counselling and control groups.

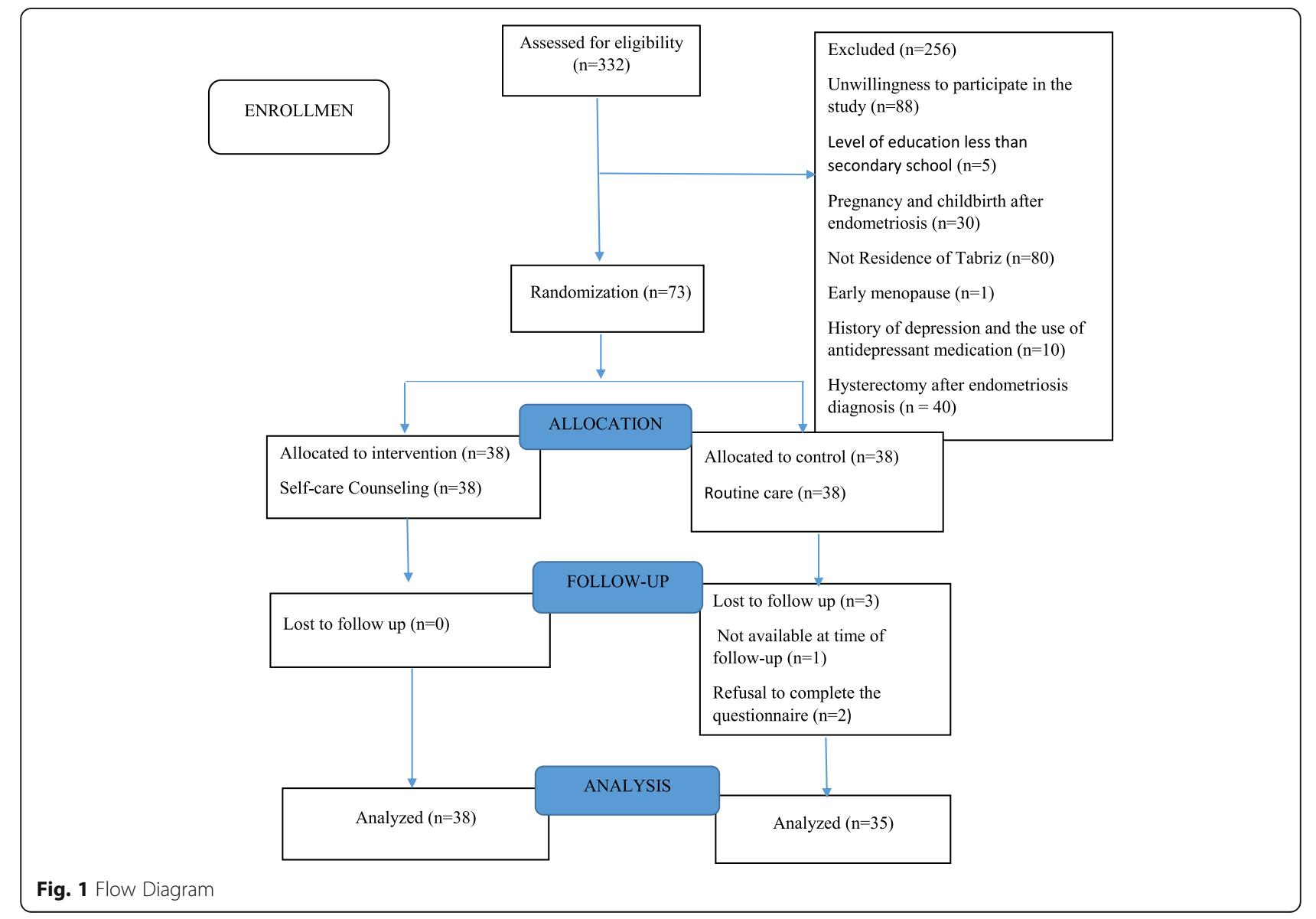


Table 1 Socio-demographic characteristics of the participants in the study groups

\begin{tabular}{|c|c|c|c|}
\hline Variable & $\begin{array}{l}\text { Counselling group } \\
(n=38) \\
N(\%)\end{array}$ & $\begin{array}{l}\text { Control group } \\
(n=38) \\
N(\%)\end{array}$ & $P$-Value \\
\hline Age $\left(\right.$ year) ${ }^{a}$ & $34.8(6.0)$ & $34.0(6.2)$ & $0.539^{\dagger}$ \\
\hline Marital Status & & & $0.338^{\#}$ \\
\hline Widow & $1(2.6)$ & $0(0.0)$ & \\
\hline Divorced & $5(13.2)$ & $2(5.3)$ & \\
\hline Married & $27(71.1)$ & $33(86.8)$ & \\
\hline Single & $5(13.2)$ & $3(7.9)$ & \\
\hline $\begin{array}{l}\text { Duration of marriage } \\
\text { (year) }^{\mathrm{a}}\end{array}$ & $12.9(6.4)$ & $12.1(6.9)$ & $0.624^{\dagger}$ \\
\hline Number of children & & & $0.028^{\#}$ \\
\hline No child & $11(28.9)$ & $9(23.7)$ & \\
\hline One child & $6(15.8)$ & $17(44.7)$ & \\
\hline Two and more child & $14(36,8)$ & $8(21.1)$ & \\
\hline History of infertility & & & $0.804^{\ddagger}$ \\
\hline Yes & $15(39.5)$ & $14(36.8)$ & \\
\hline Willingness to re-pregnancy & & & $0.715^{\ddagger}$ \\
\hline Yes & $19(50.0)$ & $19(50.0)$ & \\
\hline Education & & & $0.464^{\S}$ \\
\hline Secondary school & $12(31.6)$ & $11(28.9)$ & \\
\hline Diploma & $17(44.8)$ & $15(39.4)$ & \\
\hline University & $9(23.7)$ & $12(31.6)$ & \\
\hline Job & & & $0.509^{\#}$ \\
\hline Housewife & $28(73.7)$ & $27(71.1)$ & \\
\hline Employed & $10(26.3)$ & $11(28.9)$ & \\
\hline Husband's Education & & & $0.046^{\S}$ \\
\hline Illiterate & $0(0.0)$ & $1(2.6)$ & \\
\hline Primary school & $8(21.1)$ & $3(7.9)$ & \\
\hline Secondary school & $7(18.4)$ & $5(13.2)$ & \\
\hline Diploma & $9(23.7)$ & $13(34.2)$ & \\
\hline University & $5(13.2)$ & $11(28.9)$ & \\
\hline Husband's Job & & & $0.859^{\#}$ \\
\hline Unemployed & $2(5.3)$ & $1(2.6)$ & \\
\hline Employee & $3(7.9)$ & $6(15.8)$ & \\
\hline Worker & $7(18.4)$ & $9(23.7)$ & \\
\hline Other & $17(44.7)$ & $17(44.7)$ & \\
\hline Income sufficiency & & & $0.185^{\S}$ \\
\hline Enough & $7(18.4)$ & $10(26.3)$ & \\
\hline Not enough & $12(31.6)$ & $7(18.4)$ & \\
\hline Relatively enough & $19(50.0)$ & $21(55.3)$ & \\
\hline House status & & & $0.904^{\#}$ \\
\hline Personal & $19(50.0)$ & $23(60.5)$ & \\
\hline Rental & $10(26.3)$ & $8(21.1)$ & \\
\hline Woman's parents' house & $2(5.3)$ & $2(5.3)$ & \\
\hline Husband's parents' house & $7(18.4)$ & $5(13.2)$ & \\
\hline
\end{tabular}


Table 1 Socio-demographic characteristics of the participants in the study groups (Continued)

\begin{tabular}{|c|c|c|c|}
\hline Variable & $\begin{array}{l}\text { Counselling group } \\
(n=38) \\
N(\%)\end{array}$ & $\begin{array}{l}\text { Control group } \\
(n=38) \\
\mathrm{N}(\%) \\
\end{array}$ & P-Value \\
\hline Satisfaction with marital status & & & $0.264^{\S}$ \\
\hline Satisfied & $22(57.9)$ & $26(68.4)$ & \\
\hline Relatively satisfied & $5(13.2)$ & $4(10.5)$ & \\
\hline Dissatisfied & $2(5.3)$ & $3(7.9)$ & \\
\hline Duration of Endometriosis Diagnosis (Year) ${ }^{a}$ & $3.9(2.2)$ & $3.3(1.9)$ & $0.179^{\dagger}$ \\
\hline Treatment & & & $0.719^{\#}$ \\
\hline Laparoscopy & $29(76.3)$ & $32(84.2)$ & \\
\hline Laparoscopy+ medical & $6(15.8)$ & $5(13.2)$ & \\
\hline Laparoscopy+ medical+ Herbal & $2(5.3)$ & $1(2.6)$ & \\
\hline Laparoscopy+ herbal & $1(2.6)$ & $0(0.0)$ & \\
\hline Post treatment condition & & & $0.105^{\ddagger}$ \\
\hline Recover & $32(84.2)$ & $26(63.4)$ & \\
\hline Recurrence & $6(15.8)$ & $12(31.6)$ & \\
\hline
\end{tabular}

${ }^{\text {sTrend Chi-square test, }}{ }^{\dagger}$ Independent T-test ${ }^{\#}$ Fisher exact test ${ }^{\ddagger}$ Chi-square test

${ }^{a}$ Numbers are reported in mean (standard deviation)

There was a significant difference between the counselling and control groups in terms of physical health before the intervention according to the independent $\mathrm{t}$-test $(p<0.05)$. The mean (standard deviation) score of physical health was 55.0 (8.1) before the intervention, whereas it was 58.9 (4.9) 4 weeks after the intervention in the counselling group. The mean (standard deviation) score of physical health was 43.8 (6.6) before the intervention, whereas it was 39.5 (5.4) 4 weeks after the intervention in the control group. The ANCOVA test results showed significant differences between the two groups in terms of physical health score by controlling baseline values (mean difference $=17.2,95 \%$ confidence interval: from 13.8 to $20.5, p<0.001$ ). There was a significant difference between the counselling and control groups in terms of mental health before the intervention $(p<0.05)$. The mean (standard deviation) of mental health score was 53.3 (6.2) before the intervention, whereas it was 57.1 (4.8) 4 weeks after the intervention in the counselling group. The mean (standard deviation) of mental health score was 47.5 (7.5) before the intervention, whereas it was 44.7 (4.8) 4 weeks after the intervention in the control group. The ANCOVA test results showed a significant difference between the two groups in terms of mental health score by controlling baseline values (mean difference $=12.0,95 \%$ confidence interval: -9.0 to $14.9, p<0.001$ ) (Table 5).

\section{Discussion}

The research results showed a significant reduction in the mean score of anxiety 4 weeks after the intervention in the counselling group in comparison with that of the control group. Furthermore, the mean score of quality of life was significantly higher in the counselling group than in the control group.

Several studies reported that endometriosis was associated with a reduction in some aspects of mental functioning, mental health, and quality of life and that women with endometriosis suffered from depression (86\%), moderate to severe anxiety (29\%), and mood disorders $(68 \%)$. The prevalence rates of these disorders were much higher in these patients than in the general population [52]. Since endometriosis is chronic in nature and does not have a specific treatment, controlling its symptoms depends partially on the individual

Table 2 Comparison of mean depression scores before and 4 weeks after intervention between counselling and control groups

\begin{tabular}{llll}
\hline $\begin{array}{l}\text { Variable } \\
\text { Depression }\end{array}$ & $\begin{array}{l}\text { Counselling group } \\
(\mathrm{N}=38) \\
\text { median (first and third quartiles) }\end{array}$ & $\begin{array}{l}\text { Control group } \\
(\mathrm{N}=38) \\
\text { median (first and third quartiles) }\end{array}$ \\
\hline Pre intervention & $18.0(14.7-30.0)$ & $17.0(14.7-25.2)$ & $0.645^{\mathrm{a}}$ \\
Post intervention & $12.0(7.7-23.0)$ & $11.0(7.0-19.0)$ & $0.565^{\mathrm{a}}$ \\
\hline
\end{tabular}

a Due to the abnormal distribution, the Mann-Whitney $\mathrm{U}$ test was used and the median (first and third quartiles) was reported The depression score range is $0-63$ 
Table 3 Comparison of mean state and trait anxiety scores before and 4 weeks after intervention between counselling and control groups

\begin{tabular}{|c|c|c|c|c|}
\hline \multirow[t]{2}{*}{ Variable } & \multirow{2}{*}{$\begin{array}{l}\text { Counselling group } \\
\text { Mean (SD) } \\
(n=38)\end{array}$} & \multicolumn{3}{|c|}{ Control group } \\
\hline & & $\begin{array}{l}\text { Mean (SD) } \\
(n=38)\end{array}$ & Mean difference (95\% confidence interval) & $p$-value \\
\hline \multicolumn{5}{|l|}{ State anxiety } \\
\hline Pre intervention & $44.8(10.4)$ & $43.2(10.6)$ & $1.6(-3.2$ to 6.4$)$ & 0.507 \\
\hline Post intervention & $35.1(8.0)$ & $47.1(10.2)$ & $-12.0(-14.4$ to -9.6$)$ & $<0.001$ \\
\hline \multicolumn{5}{|l|}{ Trait anxiety } \\
\hline Pre intervention & $44.9(9.9)$ & $41.7(8.8)$ & $3.2(-1.0$ to 7.5$)$ & 0.136 \\
\hline Post intervention & $37.0(8.2)$ & $45.6(9.1)$ & $-10.9(-12.7$ to -9.1$)$ & $<0.001$ \\
\hline
\end{tabular}

For comparison of groups before intervention Independent t-test and after intervention, ANCOVA test with controlled baseline values was used

The range of state and trait anxiety scores is $20-80$

Table 4 Qualitative comparison of depression, state and trait anxiety levels before and 4 weeks after intervention between counselling and control groups

\begin{tabular}{|c|c|c|c|}
\hline Variable & $\begin{array}{l}\text { Counselling group } \\
\mathrm{n}(\%)\end{array}$ & $\begin{array}{l}\text { Control group } \\
\mathrm{n}(\%)\end{array}$ & $p$-value \\
\hline \multicolumn{4}{|c|}{ Depression (Pre intervention) } \\
\hline Mild & $24(63.2)$ & $22(57.9)$ & 0.641 \\
\hline Moderate & $14(36.8)$ & $16(42.1)$ & \\
\hline \multicolumn{4}{|c|}{ Depression (Post intervention) } \\
\hline minimal & $24(63.2)$ & $21(55.3)$ & 0.859 \\
\hline Mild & $3(7.9)$ & $7(8.4)$ & \\
\hline Moderate & $11(28.9)$ & $7(18.4)$ & \\
\hline \multicolumn{4}{|c|}{ State anxiety (Pre intervention) } \\
\hline Moderate & $29(76.3)$ & $31(81.6)$ & 0.553 \\
\hline Relatively severe & $7(18.4)$ & $6(15.8)$ & \\
\hline Severe & $2(5.3)$ & $1(2.6)$ & \\
\hline \multicolumn{4}{|c|}{ State anxiety (Post intervention) } \\
\hline Mild & $16(42.1)$ & $1(2.6)$ & $<0.001$ \\
\hline Moderate & $22(57.9)$ & $25(65.8)$ & \\
\hline Relatively severe & $0(0.0)$ & $6(15.8)$ & \\
\hline Severe & $0(0.0)$ & $3(7.9)$ & \\
\hline \multicolumn{4}{|c|}{ Trait anxiety (Pre intervention) } \\
\hline Moderate & $30(78.9)$ & $31(81.6)$ & 0.735 \\
\hline Relatively severe & $7(18.4)$ & $7(18.4)$ & \\
\hline Severe & $1(2.6)$ & $0(0.0)$ & \\
\hline \multicolumn{4}{|c|}{ Trait anxiety (Post intervention) } \\
\hline Mild & $14(36.8)$ & $0(0.0)$ & $<0.001$ \\
\hline Moderate & $22(57.9)$ & $28(73.7)$ & \\
\hline Relatively severe & $2(5.3)$ & $5(13.2)$ & \\
\hline Severe & $0(0.0)$ & $2(5.3)$ & \\
\hline
\end{tabular}

"Mann-Whitney U test themselves. Apparently, it is essential to design self-care programs.

The effect of self-care counselling on mental health and quality of life in women with endometriosis had not been assessed previously. Therefore, similar studies are reviewed here:

Zhao et al. assessed the impact of progressive muscle relaxation on depression, anxiety, and quality of life in a randomized clinical trial. They examined 100 Chinese women with endometriosis aged between 18 and 48 years undergoing agonist therapy. The therapy lasted for 12 weeks, significantly reduced depression and anxiety, and improved quality of life in the intervention group [17]. The results of their study were consistent with the results of the present study, except for the depression variable. However, the type of intervention and the sample size were different in these two studies.

Alhayek et al. assessed the impact of a certain training program on anxiety and depression in a prospective study in Saudi Arabia. They examined 104 diabetic patients from May 2011 to October 2012. The training program was a videotape regarding diabetes and individual counselling sessions. Depression decreased significantly in the patients after 6 months [53]. The results of their study were inconsistent with the results of the present study. There were no control group and group counselling in the former study, and the target group was not women with endometriosis.

Self-care training courses offer a broad insight into individuality, objective, and life. It encourages people to accept their conditions and act rationally. It guides them to pursue and promote self-care practices [37]. Various aspects of self-care (e.g. diet, physical exercise, and pain control) were discussed in the counselling sessions of the present study which may promote self-control practices and self-care behavior and help the patients to control anxiety. Thus, a significant improvement was observed in women with endometriosis of the counselling group. 
Table 5 Comparison of mean quality of life scores before and 4 weeks after intervention between counselling and control groups

\begin{tabular}{|c|c|c|c|c|c|}
\hline Variable & & Counselling group & Control group & & \\
\hline Quality of life & & $\begin{array}{l}\text { Mean (SD) } \\
(n=38)\end{array}$ & $\begin{array}{l}\text { Mean (SD) } \\
(n=38)\end{array}$ & Mean difference ( $95 \%$ confidence interval) & P-Value \\
\hline \multirow{2}{*}{$\begin{array}{l}\text { Physical Health } \\
\text { Field }\end{array}$} & Pre intervention & $55.0(8.1)$ & $43.8(6.6)$ & $11.3(7.8$ to 14.7$)$ & $<0.001$ \\
\hline & Post intervention & $58.9(4.9)$ & $39.5(5.4)$ & $17.2(13.8$ to 20.5$)$ & $<0.001$ \\
\hline \multirow[t]{2}{*}{ Mental health field } & Pre intervention & $53.3(6.2)$ & $47.5(7.5)$ & 5.8 (2.6 to 9.0$)$ & $<0.001$ \\
\hline & Post intervention & $57.1(4.8)$ & $44.7(4.8)$ & $12.0(9.0$ to 14.9$)$ & $<0.001$ \\
\hline
\end{tabular}

For comparison of groups before intervention Independent t-test and after intervention, ANCOVA test with controlled baseline values was used

The range of quality of life scores is $0-100$

There was no significant difference in terms of depression between the counselling and control groups after the intervention in the present study. Counselling did not decrease depression since the chronic endometriosis with no definitive treatment and associated complications (e.g. infertility and stress) significantly increased depression. Probably, the intervention was not efficient enough to resolve many of these tensions.

The results of the present study showed improvement in quality of life after the intervention in the counselling group compared to the control group. The followings are several similar studies in line with the results of the present study in different patients:

A semi experimental study assessed the effects of educational interventions on sexual function and quality of life of 138 women with endometriosis. The intervention improved sexual function and quality of life of these women [54]. The results of this study were consistent with the results of the present study, and the main component of self-care counselling was identified as training and providing necessary information to patients.

A similar semi-experimental study aimed to assess the effect of self-care training on the quality of life of 60 diabetic patients at Seyed Al-Shohada Treatment Center of Tehran. The results showed that proper training on prevention and treatment of diabetes promoted self-care practices, improved public health, and enhanced quality of life of diabetic patients [55]. The results of this study were consistent with the results of the present study. However, the target group and type of intervention were different in the two studies.

Heidari et al. assessed 60 elderly people residing in the Omid Elderly Care Center of Brujen in a controlled randomized trial. They reported that self-care training program for the elderly (proper diet, physical exercise, sleep, and medication) improved their quality of life [56]. Narimani et al. assessed 32 dialysis patients in Maragheh in a semi-experimental study. They reported that self-care training in hemodialysis patients improved their quality of life [57].

To interpret the results, it is fair to state that self-care education improved patients' information and feelings about the disease and its conditions, the ability to cope with daily life, and the development of self-care behavior promoting inner satisfaction, psychological well-being, and self-efficacy (components of quality of life) [58-60].

Therefore, the present study enriches the research literature on endometriosis by showing that counselling with a self-care approach can improve the anxiety and quality of life among these patients. The patients are eager to acquire information and have self-control on their health problems; therefore, the existence of a multidisciplinary team in managing this disease and integrating self-care counselling programs into the routine care of these patients would be necessary and may promote the health of individuals, families, and societies.

\section{Limitations and strengths}

All participants were literate in this study; therefore, the results cannot be generalized to the population of illiterate women. The research strengths included adherence to all principles of clinical trial (e.g. random allocation and concealment of allocation), completion of the questionnaires by the researcher, and removal of incomplete, false, and ignored items and responses. Moreover, during the counselling sessions, the native language of participants was employed to communicate more easily with them.

\section{Conclusion}

The results showed that self-care counselling might reduce anxiety and improve the quality of life of women with endometriosis. Healthcare providers can use this method of counselling along with other therapies and routine care for women with endometriosis to improve the outcomes of their illness, enhance mental health, and promote the quality of life.

\section{Abbreviations}

BDI: Beck Depression Inventory; STAI: State-Trait Anxiety Inventory; SF36: Short Form Healthy Survey (36 items)

\section{Acknowledgments}

We thank the Vice Chancellor for Research and Technology of Tabriz University of Medical Sciences, staff of Al-Zahra Educational and Medical Center and women with endometriosis who participated in the study. 


\section{Authors' contributions}

NF implemented the study and was responsible for data collection and wrote the first draft of the manuscript. SHH and MM contributed in the study design and data analysis, assisted in the preparation of the final version of the manuscript, KHE designed the counseling protocol. The authors read and approved the final version of the manuscript.

\section{Funding}

The project was financed by Tabriz University of Medical Sciences (Grant No. 61669). The funding was spent on sampling and conducting the study.

\section{Availability of data and materials}

Data and materials of this study are available from the corresponding author upon reasonable request.

\section{Ethics approval and consent to participate}

All participants were informed about the study and written informed consent was obtained from them (Consent to participate was obtained from the parents/guardians for participants under 16 years old). The Ethics Committee of Tabriz University of Medical Sciences confirmed the study (ethical code: REC.1397, 625 TBZMED.IR).

\section{Consent for publication}

Not applicable.

\section{Competing interests}

The authors declare that they have no competing interests.

\section{Author details}

${ }^{1}$ Student Research Committee, Midwifery Department, Nursing and Midwifery Faculty, Tabriz University of Medical Sciences, Tabriz, Iran. 2Women's Reproductive Health Research Center, Tabriz University of Medical Sciences, Tabriz, Iran. ${ }^{3}$ Midwifery Department, Social Determinants of Health Research Center, Tabriz University of Medical Sciences, Tabriz, Iran. ${ }^{4}$ Faculty of Education and Psychology, University of Tabriz, Tabriz, Iran.

\section{Received: 19 April 2020 Accepted: 22 July 2020}

\section{Published online: 29 July 2020}

\section{References}

1. Butticè $S$, Laganà AS, Barresi V, Inferrera $A$, Mucciardi G, Di Benedetto $A$, et al. Lumbar ureteral stenosis due to endometriosis: our experience and review of the literature. Case Rep Urol. 2013;2013:1-5.

2. Rogers PA, D'Hooghe TM, Fazleabas A, Gargett CE, Giudice LC, Montgomery GW, et al. Priorities for endometriosis research: recommendations from an international consensus workshop. Reprod Sci. 2009;16(4):335-46.

3. Macer ML, Taylor HS. Endometriosis and infertility: a review of the pathogenesis and treatment of endometriosis-associated infertility. Obstetrics Gynecol Clin. 2012;39(4):535-49.

4. Laganà AS, Vitale SG, Salmeri FM, Triolo O, Frangež HB, Vrtačnik-Bokal E, et al. Unus pro omnibus, omnes pro uno: a novel, evidence-based, unifying theory for the pathogenesis of endometriosis. Med Hypotheses. 2017;103: $10-20$.

5. Lagana AS, Salmeri FM, Ban Frangež H, Ghezzi F, Vrtačnik-Bokal E, Granese R. Evaluation of $\mathrm{M} 1$ and $\mathrm{M} 2$ macrophages in ovarian endometriomas from women affected by endometriosis at different stages of the disease. Gynecol Endocrinol. 2020;36(5):441-4.

6. Laganà AS, Garzon S, Götte M, Viganò P, Franchi M, Ghezzi F, et al. The pathogenesis of endometriosis: molecular and cell biology insights. Int J Mol Sci. 2019;20(22):5615.

7. Vitale SG, Capriglione S, Peterlunger I, La Rosa VL, Vitagliano A, Noventa M et al. The role of oxidative stress and membrane transport systems during endometriosis: a fresh look at a busy corner. Oxid Med Cell Longev. 2018; 2018:1-15

8. Kennedy S, Bergqvist A, Chapron C, D'Hooghe T, Dunselman G, Greb R, et al. ESHRE guideline for the diagnosis and treatment of endometriosis. Hum Reprod. 2005;20(10):2698-704

9. Fuldeore MJ, Soliman AM. Prevalence and symptomatic burden of diagnosed endometriosis in the United States: national estimates from a cross-sectional survey of 59,411 women. Gynecol Obstet Invest. 2017;82(5): 453-61.
10. Meuleman C, Vandenabeele B, Fieuws S, Spiessens C, Timmerman D, D'Hooghe T. High prevalence of endometriosis in infertile women with normal ovulation and normospermic partners. Fertil Steril. 2009;92(1):68-74.

11. Laufer M. Premenarcheal endometriosis without an associated obstructive anomaly: presentation, diagnosis, and treatment. Fertil Steril. 2000;74(3):S15.

12. Nezhat F, Datta MS, Hanson V, Pejovic T, Nezhat C, Nezhat C. The relationship of endometriosis and ovarian malignancy: a review. Fertil Steril. 2008;90(5):1559-70.

13. Tomassetti C, D'Hooghe T. Endometriosis and infertility: insights into the causal link and management strategies. Best Pract Res Clin Obstet Gynaecol. 2018:51:25-33.

14. Ballard K, Seaman H, De Vries CS, Wright J. Can symptomatology help in the diagnosis of endometriosis? Findings from a national case-control study—part 1. BJOG. 2008;115(11):1382-91.

15. Medicine PCotASfR. Treatment of pelvic pain associated with endometriosis. Fertil Steril. 2008;90(5):S260-S9.

16. Bedaiwy MA, Allaire C, Yong P, Alfaraj S. Medical management of endometriosis in patients with chronic pelvic pain. In: Seminars in reproductive medicine. New York: Thieme Medical Publishers; 2017.

17. Zhao L, Wu H, Zhou X, Wang Q, Zhu W, Chen J. Effects of progressive muscular relaxation training on anxiety, depression and quality of life of endometriosis patients under gonadotrophin-releasing hormone agonist therapy. Eur J Obstet Gynecol Reprod Biol. 2012;162(2):211-5.

18. Vitale SG, La Rosa VL, Rapisarda AMC, Lagana AS. Impact of endometriosis on quality of life and psychological well-being. J Psychosom Obstet Gynecol. 2017;38(4):317-9.

19. Facchin F, Barbara G, Saita E, Mosconi P, Roberto A, Fedele L, et al. Impact of endometriosis on quality of life and mental health: pelvic pain makes the difference. J Psychosom Obstet Gynecol. 2015;36(4):135-41.

20. Carvalho AC, Poli Neto OB, Crippa JAS, Hallak JEC, Osorio FL. Associations between chronic pelvic pain and psychiatric disorders and symptoms. Arch Clin Psychiatry (São Paulo). 2015;42(1):25-30.

21. Pope CJ, Sharma V, Sharma S, Mazmanian D. A systematic review of the association between psychiatric disturbances and endometriosis. J Obstet Gynaecol Can. 2015;37(11):1006-15.

22. Fourquet J, Báez L, Fiqueroa M, Iriarte RI, Flores I. Quantification of the impact of endometriosis symptoms on health-related quality of life and work productivity. Fertil Steril. 2011;96(1):107-12.

23. Chaman-Ara K, Bahrami MA, Bahrami E. Endometriosis psychological aspects: a literature review. J Endometriosis Pelvic Pain Dis. 2017;9(2):105-11.

24. Huntington A, Gilmour JA. A life shaped by pain: women and endometriosis. J Clin Nurs. 2005;14(9):1124-32.

25. Gilmour JA, Huntington A, Wilson HV. The impact of endometriosis on work and social participation. Int J Nurs Pract. 2008;14(6):443-8.

26. Cavaggioni G, Lia C, Resta S, Antonielli T, Benedetti Panici P, Megiorni F, et al. Are mood and anxiety disorders and alexithymia associated with endometriosis? A preliminary study. Biomed Res Int. 2014;2014:1-5.

27. Laganà AS, La Rosa V, Petrosino B, Vitale SG. Comment on "risk of developing major depression and anxiety disorders among women with endometriosis: a longitudinal follow-up study". J Affect Disord. 2017;208:672-3.

28. Laganà AS, Condemi I, Retto G, Muscatello MRA, Bruno A, Zoccali RA, et al. Analysis of psychopathological comorbidity behind the common symptoms and signs of endometriosis. Eur J Obstet Gynecol Reprod Biol. 2015;194:30-3.

29. Burkman RT. Berek \& Novak's gynecology. JAMA. 2012;308(5):516-7.

30. Sepulcri RP, do Amaral VF. Depressive symptoms, anxiety, and quality of life in women with pelvic endometriosis. Eur J Obstet Gynecol Reprod Biol. 2009;142(1):53-6.

31. Briggs LA, Kirchhoff KT, Hammes BJ, Song M-K, Colvin ER. Patient-centered advance care planning in special patient populations: a pilot study. J Prof Nurs. 2004;20(1):47-58

32. Höglund AT, Winblad U, Arnetz B, Arnetz JE. Patient participation during hospitalization for myocardial infarction: perceptions among patients and personnel. Scand J Caring Sci. 2010;24(3):482-9.

33. Macdonald W, Rogers A, Blakeman T, Bower P. Practice nurses and the facilitation of self-management in primary care. J Adv Nurs. 2008;62(2):191-9.

34. Smith J, Liles C. Information needs before hospital discharge of myocardial infarction patients: a comparative, descriptive study. J Clin Nurs. 2007;16(4): $662-71$

35. Leino-Kilpi H, Johansson K, Heikkinen K, Kaljonen A, Virtanen H, Salanterä S. Patient education and health-related quality of life: surgical hospital patients as a case in point. J Nurs Care Qual. 2005;20(4):307-16. 
36. Bodenheimer T, Lorig K, Holman H, Grumbach K. Patient self-management of chronic disease in primary care. Jama. 2002;288(19):2469-75.

37. Lorig KR, Holman HR. Self-management education: history, definition, outcomes, and mechanisms. Ann Behav Med. 2003;26(1):1-7.

38. Organization WH. Self care for health: a handbook for community health workers \& volunteers. New Delhi: World Health Organization, Regional Office for South-East Asia; 2013. p. 15.

39. Ibrahim A, Tawfik FM, Abudari MO. Using a self-care management tool to improve self-care and quality of life in patients with congestive heart failure. Clin Nurs Stud. 2016;4(3):1-17.

40. Schaefer J, Miller D, Goldstein M, Simmons L. Partnering in selfmanagement support: a toolkit for clinicians. Cambridge: Institute for Healthcare Improvement; 2009.

41. Brown J, Farquhar C. Endometriosis: an overview of Cochrane reviews. Cochrane Database Syst Rev. 2014:(3). Available in: https://www.cochrane. org/CD009590/MENSTR_endometriosis-an-overview-of-cochrane-reviews.

42. Sinaii N, Cleary SD, Younes N, Ballweg ML, Stratton P. Treatment utilization for endometriosis symptoms: a cross-sectional survey study of lifetime experience. Fertil Steril. 2007;87(6):1277-86.

43. Banikarim C, Chacko MR, Kelder SH. Prevalence and impact of dysmenorrhea on Hispanic female adolescents. Arch Pediatr Adolesc Med. 2000;154(12):1226-9.

44. Kordi M, Banaei M, Asgharipour N, Mazloum SR, Akhlaghi F. Prediction of self-care behaviors of women with gestational diabetes based on belief of person in own ability (self-efficacy). Iranian J Obstet Gynecol Infertil. 2016; 19(13):6-17.

45. Waller KG, Shaw RW. Endometriosis, pelvic pain, and psychological functioning. Fertil Steril. 1995;63(4):796-800.

46. Valizadeh S, Aliafsari E, Moghbeli G, Soheili A. Applicablity of orem's self-care model in Iran: an integrated review. J Urmia Nurs Midwifery Fac. 2017;15(4): 313-28.

47. Beck A, Steer R, Brown G. Manual for the Beck depression inventory-II (BDIII); 1996.

48. Rajabi G, Karjo KS. Psychometric properties of a Persian-language version of the beck depression inventory-second edition (BDI-II-Persian); 2013.

49. Spielberger CD. State-trait anxiety inventory for adults; 1983.

50. Mahram B. Validity and reliability of Spielberger anxiety test in Mashhad city. Tehran: Allame Tabatabayee University; 1998.

51. Montazeri A, Goshtasebi A, Vahdaninia M, Gandek B. The short form health survey (SF-36): translation and validation study of the Iranian version. Qual Life Res. 2005;14(3):875-82.

52. Van Niekerk L, Weaver-Pirie B, Matthewson M. Psychological interventions for endometriosis-related symptoms: a systematic review with narrative data synthesis. Arch Womens Ment Health. 2019;22(6):1-13.

53. Al Hayek AA, Robert AA, Al Dawish MA, Zamzami MM, Sam AE, Alzaid AA. Impact of an education program on patient anxiety, depression, glycemic control, and adherence to self-care and medication in type 2 diabetes. J Fam Community Med. 2013;20(2):77.

54. Sayed HAE, Aboud SAHH. Effect of an educational intervention on quality of life and sexual function in women with endometriosis. Int I Studies Nurs. 2018;3(2):127.

55. Pour JS, Jafari M, Asgar MG, Dardashti HD, Teymoorzadeh E. The impact of self-care education on life quality of diabetic patients. J Health Admin (JHA). 2013;16(52).

56. Heidari $M$, Shahbazi $S$. Effect of self-care training program on quality of life of elders. Iran J Nurs. 2012;25(75):1-8.

57. Narimani K. A study of the effect of self-care training on the hemodialysis patients'quality of life; 2009

58. Scain SF, Friedman R, Gross JL. A structured educational program improves metabolic control in patients with type 2 diabetes. Diabetes Educ. 2009; 35(4):603-11.

59. Alp A, Kanat E, Yurtkuran M. Efficacy of a self-management program for osteoporotic subjects. Am J Phys Med Rehabil. 2007;86(8):633-40,

60. Nitzke S, Kritsch K, Boeckner L, Greene G, Hoerr S, Horacek T, et al. A stagetailored multi-modal intervention increases fruit and vegetable intakes of low-income young adults. Am J Health Promot. 2007;22(1):6-14.

\section{Publisher's Note}

Springer Nature remains neutral with regard to jurisdictional claims in published maps and institutional affiliations.

Ready to submit your research? Choose BMC and benefit from:

- fast, convenient online submission

- thorough peer review by experienced researchers in your field

- rapid publication on acceptance

- support for research data, including large and complex data types

- gold Open Access which fosters wider collaboration and increased citations

- maximum visibility for your research: over $100 \mathrm{M}$ website views per year

At BMC, research is always in progress.

Learn more biomedcentral.com/submissions 